\title{
Polytypic and polymorphic cytogenetic variations in the widespread anuran Physalaemus cuvieri (Anura, Leiuperidae) with emphasis on nucleolar organizing regions
}

\author{
YEDA R. S. D. QUINDERÉ ${ }^{1}$, LUCIANA B. LOURENÇO $^{1}$, GILDA V. ANDRADE$^{2}$, \\ CRISTIAN TOMATIS ${ }^{3}$, DIEGO BALDO ${ }^{3}$ and SHIRLEI M. RECCO-PIMENTEL ${ }^{1}$
}

\footnotetext{
${ }^{1}$ Departamento de Biologia Celular, Instituto de Biologia, CP6109, Universidade Estadual de Campinas UNICAMP, 13083-863, Campinas, SP, Brasil.

${ }^{2}$ Departamento de Biologia, Centro de Ciências Biológicas e da Saúde, Universidade Federal do MaranhãoUFMA, 65080-040 São Luís, MA, Brasil.

${ }^{3}$ Laboratorio de Genética Evolutiva y Molecular, Universidad Nacional de Misiones, CP 3300 ,

Posadas,Misiones, Argentina.
}

\begin{abstract}
We investigated the NOR distribution in ten populations of Physalaemus cuvieri from different regions of Brazil and Argentina. A high variability in NOR pattern was observed and provided a useful tool in grouping several populations. The specimens from the state of Tocantins, northern Brazil, could easily be distinguished from all the other analyzed populations, since its karyotype presented NORs in the chromosome pairs 1, 3, 4 and 10 (and sometimes also in chromosome 5), and several pericentromeric C-bands. A NOR-site in chromosome 9 characterized three populations from the northeastern region of Brazil. Interestingly, the $P$. cuvieri populations located in opposite extremes of the geographic distribution had, as a fixed condition, the presence of NORs in $8 \mathrm{q}$ int and $11 \mathrm{p}$. Besides interpopulational divergences, intrapopulational variability was observed in the number of NORs, except for populations from the states of Bahia and Minas Gerais, which are boundary states respectively in the northeastern and southeastern regions of Brazil. In relation to NOR size, interindividual variations occurred in all Brazilian and Argentinean populations. Additionally, intraindividual variability in NOR size was detected in specimens from Minas Gerais. The data presented herein revealed substantial geographic polytypic variation in $P$. cuvieri and indicated that a taxonomic reexamination of this species is necessary.
\end{abstract}

Key terms: Anura, chromosome, cytogenetics, NOR, Physalaemus, polymorphic variations, polytypic variations.

\section{INTRODUCTION}

The frog genus Physalaemus in South America belongs to the family Leiuperidae, together with Edalorhina, Engystomops, Eupemphix, Pleurodema, Pseudopaludicola and Somuncuria (Grant et al., 2006). Currently, the Physalaemus comprises 41 species that are distributed east of the Andes (Frost, 2007). These species were classified in seven phenetic groups: "albifrons", "cuvieri", "deimaticus", "gracilis", "henselii", "olfersii" and "signifer" (Nascimento et al., 2005). Thus far, no phylogenetic intrageneric relationships have been proposed for Physalaemus.

The species Physalaemus cuvieri is widely distributed throughout South America, occurring in the northeastern, central, and southern regions of Brazil, Misiones and Corrientes in Argentina, eastern Paraguay, Department of Santa Cruz in Bolivia and possibly lowlands of

Corresponding author: Luciana B. Lourenço, Departamento de Biologia Celular, Instituto de Biologia, CP6109, Universidade Estadual de Campinas - UNICAMP, 13083-863, Campinas, SP, Brasil, e-mail: bolsoni@unicamp.br, phone: +551935216108, fax: +551935216110. 
southern Venezuela (Cei, 1980; Manzano et al., 2004; Frost, 2007). Intraspecific morphological variation has been reported for this species. In Brazil, where P. cuvieri occupies a large geographical area, Barreto $\&$ Andrade (1995) observed that populations of the northeastern and southeastern regions reproduce in different seasons. These populations are similar regarding their reproductive biology and the seasonal differences seem to be related to the distinct climatic patterns of those regions.

In previous cytogenetic analyses, a marked chromosome variation in number and localization of NORs was observed among $P$. cuvieri specimens from five localities of southern and southeastern regions of Brazil (Silva et al., 1999). The objective of the present work was to further investigate interpopulational variation of $P$. cuvieri by extending the cytogenetic analysis to populations from the northern (Tocantins), northeastern (Maranhão, Ceará, and Bahia) and southeastern (Minas Gerais) regions of Brazil, and from the province of Misiones in the northeastern region of Argentina.

\section{MATERIAL AND METHODS}

P. cuvieri populations were sampled in six Brazilian and four Argentinean locations, as shown in Table I and Fig. 1. The Brazilian specimens were sampled in the states of Maranhão (MA), Ceará (CE) and Bahia (BA), in the northeastern region of Brazil, in the state of Tocantins (TO) in the northern region, and in the state of Minas Gerais (MG) in the southeastern region. Voucher specimens (Table I) were deposited in the Museu de História Natural, "Prof. Adão José Cardoso" (ZUEC), Universidade Estadual de Campinas (UNICAMP), Campinas, SP, Brazil, and in the Museu Nacional do Rio de Janeiro (MNRJ), Universidade Federal do Rio de Janeiro (UFRJ), Rio de Janeiro, RJ, Brazil. The Argentinean specimens were sampled in the province of Misiones, northeastern Argentina, and deposited in the Diego Baldo (MLP DB) collection, Museo de La
Plata, La Plata, province of Buenos Aires, Argentina.

Mitotic metaphases were obtained from suspensions of intestinal and testicular cells from frogs inoculated with colchicine $(2 \%)$ for at least 4 hours (adapted from Schmid, 1978; Schmid et al., 1979). Prior to the intestine and testes removal, the animals were deeply anesthetized. Chromosomes were conventionally stained with $10 \%$ Giemsa solution and processed by the AgNOR method (Howell \& Black, 1980) and also for fluorescence in situ hybridization (FISH) (Viegas-Péquinot, 1992) using the rDNA probe HM 123 (Meunier-Rotival et al., 1979). The C- banding technique (King, 1980) was applied to the Brazilian populations.

\section{RESULTS}

\subsection{Karyotypes of Brazilian specimens from Maranhão (MA) and Ceará (CE)}

The specimens from Urbano Santos (MA), São Pedro da Água Branca (MA) and Crateús (CE) had a diploid complement of 22 biarmed chromosomes and no sex chromosomes were identified. The chromosome pairs $1,2,5,6,10$ and 11 were metacentric, whereas the remaining pairs $(3,4,7,8$ and 9) were submetacentric (Fig. 2). Since the size and morphology of pairs 8 and 9 were very similar in these three populations, the C-banding technique was essential in distinguishing between them; pair 8 had heterochromatic bands adjacent to the secondary constriction, probably containing the NOR (Fig. 2b), whereas dark $\mathrm{C}$-bands coincided with the NORs in pair 9 (Fig 3). C-banding also revealed constitutive heterochromatin interstitially in the short arm of chromosome 5 , in the telomeric regions of chromosome pair 1 and in the centromeric regions of all the chromosomes (Fig. 2b).

The pairs 8 and 9 were NOR-bearing chromosomes in all the analyzed MA and CE specimens (Fig. 4a-m). In the specimens from São Pedro da Água Branca, there was an additional NOR site in the chromosomal pair 7 (Figs. $4 n-0$ ). The NOR on pair 8 
Sampling localities in which $P$. cuvieri populations were analyzed for polymorphism in the NOR pattern. Total numbers of studied specimens and NOR chromosomal locations detected for each population are indicated. Voucher specimen identification is indicated between parentheses. MLP DB - Diego Baldo collection; MNRJ - National Museum of Rio de Janeiro; ZUEC - Zoology Museum of the State University of Campinas; BC collection deposited in Department of Cell Biology, IB-Unicamp. Int: interstitial; p: short arm; per: pericentromeric; q: long arm; ter: terminal. Brazilian States - MA: Maranhão; CE: Ceará; BA: Bahia; MG: Minas Gerais; TO: Tocantins; SP: São Paulo; RS: Rio Grande do Sul. MN: Misiones province, Argentina.

\begin{tabular}{|c|c|c|c|}
\hline Localities & Total number of specimens & NOR locations & Biome \\
\hline $\begin{array}{l}\text { 1) Urbano Santos } \\
\text { (MA) }\end{array}$ & $\begin{array}{l}7 \delta \text { and } 1 \text { (ZUEC 13092-13095, } \\
13098,13103,13106,11939)\end{array}$ & $8 q$ int $8 q$ int $/ 9 q$ int $9 q$ int & Cerrado \\
\hline $\begin{array}{l}\text { 2) São Pedro da Água } \\
\text { Branca (MA) }\end{array}$ & $\begin{array}{l}7 \delta \text { (MNRJ 24255*, 24256, 24259, } \\
24261,24266, \text { BC 92.13, BC 92.14) }\end{array}$ & $\begin{array}{l}7 q \text { int } 7 q \text { int } / 8 q \text { int } 8 q \text { int } / \\
9 q \text { int } 9 q \text { int } *\end{array}$ & Amazon Rain Forest \\
\hline 3) Crateús (CE) & $\begin{array}{l}4 \delta \text { and } 1 \text { ( (ZUEC 13079, } 13081 \text {, } \\
13085,13088,13089)\end{array}$ & $8 q$ int $8 q$ int $/ 9 q$ int $9 q$ int & Caatinga \\
\hline 4) Palmeiras (BA) & $4 \delta^{\prime}$ and $1+$ (ZUEC 13670-13674) & $8 \mathrm{q}$ int $8 \mathrm{q}$ int & Caatinga \\
\hline 5) Uberlândia (MG) & $5 \delta^{\circ}$ (ZUEC 13366-13370) & $8 \mathrm{q}$ int $8 \mathrm{q}$ int $* *$ & Cerrado \\
\hline $\begin{array}{l}\text { 6) Porto Nacional } \\
\text { (TO) }\end{array}$ & $\begin{array}{l}8 \text { ठ (ZUEC 13374, 13376, 13378, } \\
13379,13355-13357,13359)\end{array}$ & $\begin{array}{l}1 / 3 / 4 / 5 / 10 \text {, per in all, } \\
\text { but see the text }\end{array}$ & Cerrado \\
\hline 7) Iguazu (MN) & $1 \delta$ and 1 (MLP DB 4014, 4153) & $11 \mathrm{p}$ ter 11 ter $* * 4$ & Atlantic Rain Forest \\
\hline 8) Andresito (MN) & $3 \delta^{\pi}$ (MLP DB 3037, 3247, 5183) & $11 \mathrm{p}$ ter $11 \mathrm{p}$ ter & Atlantic Rain Forest \\
\hline 9) Fachinal (MN) & $3 \delta^{7}$ (MLP DB 3705, 4192, 5273) & $11 \mathrm{p}$ ter $11 \mathrm{p}$ ter $* 4$ & Atlantic Rain Forest \\
\hline 10) Posadas, (MN) & $\begin{array}{l}4 \delta \text { (MLP DB 3049, 3138, } 5199 . \\
5200)\end{array}$ & $11 \mathrm{p}$ ter $11 \mathrm{p}$ ter $* * 4$ & Atlantic Rain Forest \\
\hline $\begin{array}{l}\text { 11-12) Boracéia (SP) } \\
\text { and Santa Maria (RS) }\end{array}$ & 3 specimens & $11 \mathrm{p}$ ter $11 \mathrm{p}$ ter & $\begin{array}{l}\text { Atlantic Rain Forest } \\
\text { and Southern Fields }\end{array}$ \\
\hline $\begin{array}{l}\text { 13-14) Two sites at } \\
\text { Rio Claro (SP) }\end{array}$ & 6 specimens & $\begin{array}{l}8 \mathrm{q} \text { int } 8 \mathrm{q} \text { int / other } \\
\text { additional sites (see } \\
\text { the text) }\end{array}$ & Atlantic Rain Forest \\
\hline 15) Itatiba (SP) ${ }^{1}$ & 1 specimen & $8 q$ int $8 q$ int & $\begin{array}{l}\text { Atlantic Rain Forest } \\
\text { and Southern Fields }\end{array}$ \\
\hline
\end{tabular}

" Except for MNRJ 24255 in which NOR was absent in the chromosome 8.

*: Except for a few metaphases in ZUEC 13368 (see Fig. 5f).

**4. Some specimens had additional NORs, which were not listed here.

${ }^{1}$ Cited from Silva et al. (1999), for comparison purpose only. 
showed a noticeable size variation among the populations (Fig. 4) and one of the specimens (MNRJ 24255) from São Pedro da Água Branca showed the presence of NOR in only one member of the chromosome pair 8 (Fig. 4n). Regarding the chromosome pair 9, an obvious polymorphism was detected in both size and number of the NOR sites in the Urbano Santos and Crateús specimens. Overall, eight patterns of NOR distribution in the chromosome 9 were detected in specimens from Urbano Santos (Figs. 4a-h), and another four patterns were observed in specimens from Crateús (Figs. 4i-1). In the specimens from Urbano Santos, FISH with the rDNA probe HM 123 was also used to confirm the existence of the smaller NORs observed with the Ag-NOR method (Fig. 4f and $\mathrm{m}$ ).

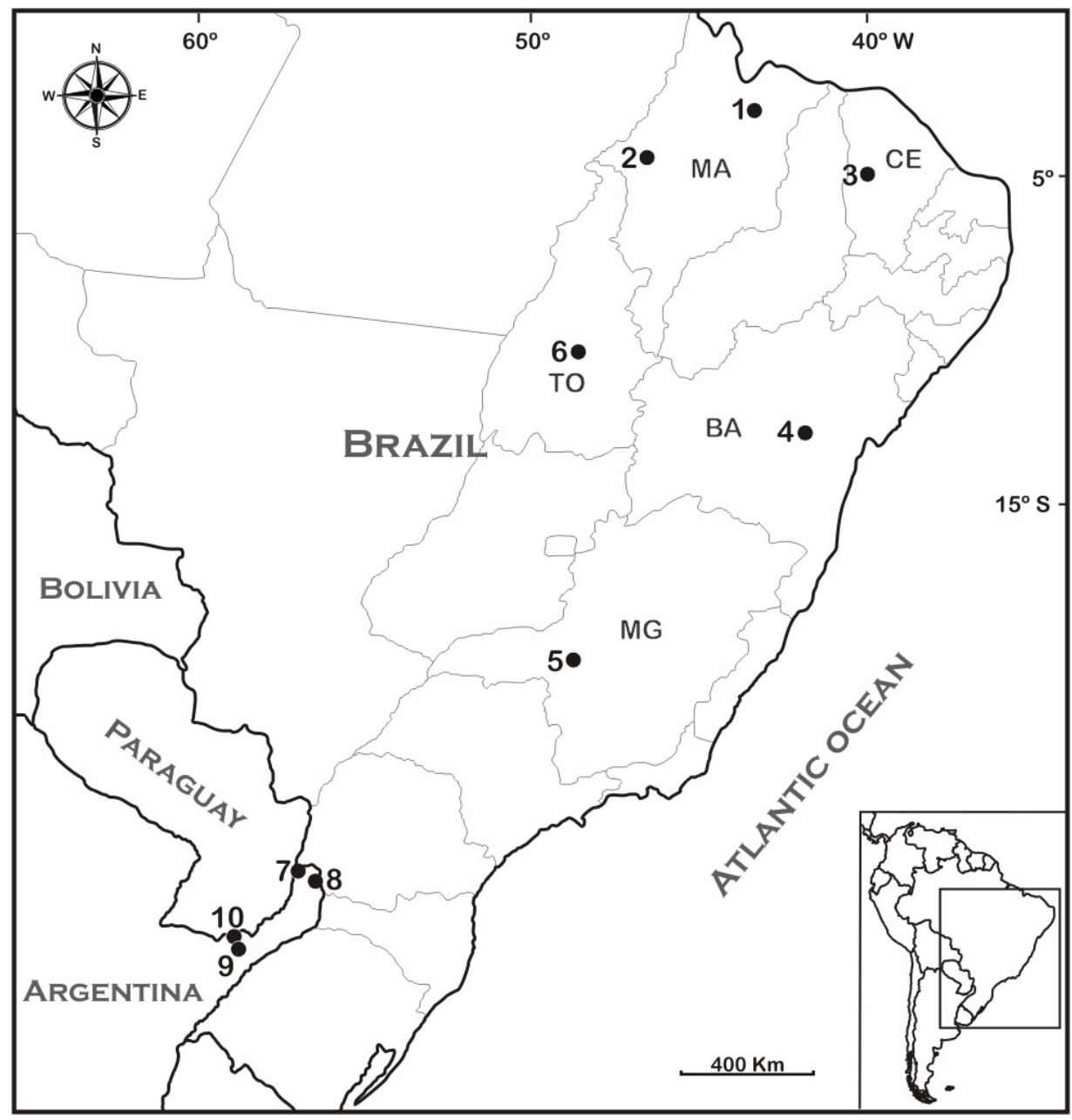

Figure 1: Partial map of South America displaying the ten localities in which the P. cuvieri specimens analyzed herein were surveyed and the other five sites analyzed by Silva et al. (1999), roughly identified by solid circles and numbers. The bold letters indicate Brazilian states: $\mathbf{B A}=$ Bahia; CE = Ceará; MA = Maranhão; MG = Minas Gerais $; \mathbf{R S ~ = ~ R i o ~ G r a n d e ~ d o ~ S u l ; ~} \mathbf{S P}=$ São Paulo; TO $=$ Tocantins. The numbers indicate districts: $\mathbf{1}=$ Urbano Santos $\left(43.4^{\circ} \mathrm{W}, 3.2^{\circ} \mathrm{S}\right) ; \mathbf{2}=$ São Pedro da Água Branca $\left(48.25^{\circ} \mathrm{W}, 5.16^{\circ} \mathrm{S}\right) ; 3$ = Crateús $\left(40.7^{\circ} \mathrm{W}, 5.3^{\circ} \mathrm{S}\right) ; 4=$ Palmeiras $\left(41.5^{\circ}\right.$ $\left.\mathrm{W}, 12.7^{\circ} \mathrm{S}\right) ; \mathbf{5}$ = Uberlândia $\left(48.3^{\circ} \mathrm{W}, 19.1^{\circ} \mathrm{S}\right) ; \mathbf{6}=$ Porto Nacional $\left(48.6^{\circ} \mathrm{W}, 10.4^{\circ} \mathrm{S}\right) ; 7$ = Iguazu,

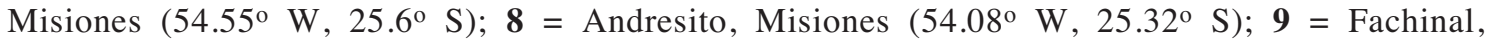
Misiones $\left(55.7^{\circ} \mathrm{W}, 27.48^{\circ} \mathrm{S}\right) ; \mathbf{1 0}=$ Posadas, Misiones $\left(55.89^{\circ} \mathrm{W}, 27.44^{\circ} \mathrm{S}\right) ; \mathbf{1 1}=$ Boracéia $(\mathrm{SP}) ; \mathbf{1 2}$ = Santa Maria (RS); 13-14 = two sites in Rio Claro (SP); 15 = Itatiba (SP). 


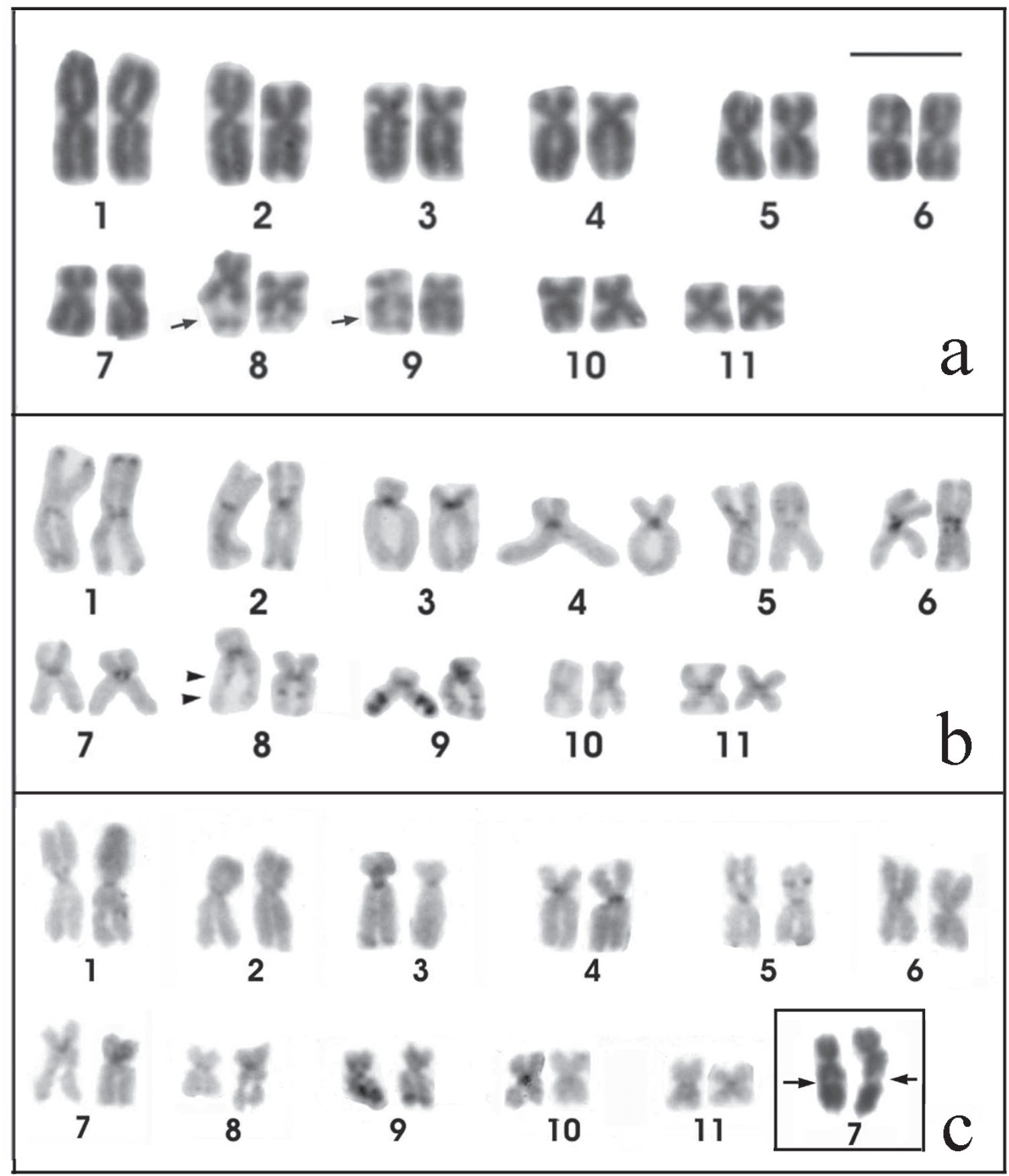

Figure 2: a-b. Karyotypes of $P$. cuvieri from Urbano Santos stained by Giemsa (a) and C-banded (b). c. Karyotype of one specimen from São Pedro da Água Branca (MA) (MNRJ 24255) after C banding. The inset shows the secondary constriction of pair 7 evidenced by Giemsa-staining. Note the heteromorphism of pair 8 in all the karyotypes. The arrows point to secondary constrictions and the arrowheads indicate the $\mathrm{C}$-bands adjcent to them in pair 8 . Bar=5 um. 


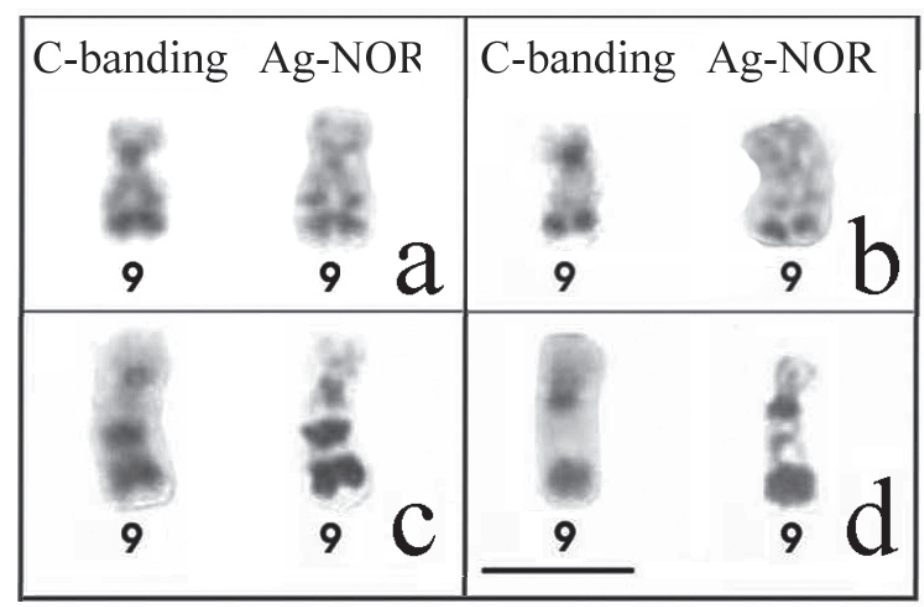

Figure 3: NOR-bearing pair 9 of four P. cuvieri specimens from Urbano Santos (MA) treated sequentially with C-banding (left) and Ag-NOR techniques (right). Note that the same regions were detected by both methods. Bar=5 um.

3.2. Karyotypes of Brazilian specimens from Bahia (BA) and Minas Gerais (MG)

The karyotypes of the specimens from Palmeiras (BA) and Uberlândia (MG) were very similar to those found in Urbano Santos (MA) and Crateús (CE). The most conspicuous difference was the absence of NOR in the chromosome pair 9 of the BA and $\mathrm{MG}$ specimens, which is metacentric in these populations instead of submetacentric as it was in all the MA and CE specimen karyotypes (Fig. 5).

In the BA and MG specimens, a NOR was detected interstitially in the long arm of pair 8, adjacent to C-bands (Fig. 5) similarly to the MA and CE specimens. However, the short arm of the pair 8 in the BA individuals showed an interstitial C-band near the centromere (Fig. 5b), which was absent in the chromosome 8 of the other specimens. Moreover, in the $\mathrm{BA}$ and $\mathrm{MG}$ specimens, like in the MA specimens, the C-banding detected an interstitial site in the short arm of chromosome 5, telomeric bands in chromosome 1 and in the centromeric regions of all the chromosomes. In the BA population interstitial C-bands near the centromere of chromosome 6 and in the short arm of chromosome 2 were also observed (Fig. 5b).

An intriguing intraindividual variation in NOR size was detected by Ag-NOR staining in five specimens from the MG population (Fig. 5e). In four of these five specimens, the variation in NOR size was also detected by FISH (Fig. 5d). Another interesting finding was the absence of NOR in one of the homologues of pair 8 and the detection by FISH of an additional NOR site in the short arm of chromosome 3 in two of the 27 metaphases analyzed of one specimen (ZUEC 13368) of this same MG population (Fig. 5f). This additional FISH signal was not detected by Ag-NOR staining, even though 26 silver-stained metaphases from this specimen were analyzed.

\subsection{Karyotypes of specimens from Argentina}

As shown in the Fig. 6a, the karyotypes of the analyzed Argentinean P. cuvieri specimens had six pairs of metacentric chromosomes (numbers 1, 2, 5, 6, 9 and 10) and five pairs of submetacentric chromosomes (numbers 3, 4, 7, 8 and 11). The Argentinean P. cuvieri karyotypes differed from all of the Brazilian specimens because their single (Figs. 6a and 6b) or principal NOR (Figs. 6c-e) was detected in the telomeric region of pair 11. Size variation for this NOR site was observed in these specimens, which was most conspicuous in the specimen from Fachinal, MLP DB 4192 (Fig. 6b). For the purpose of 


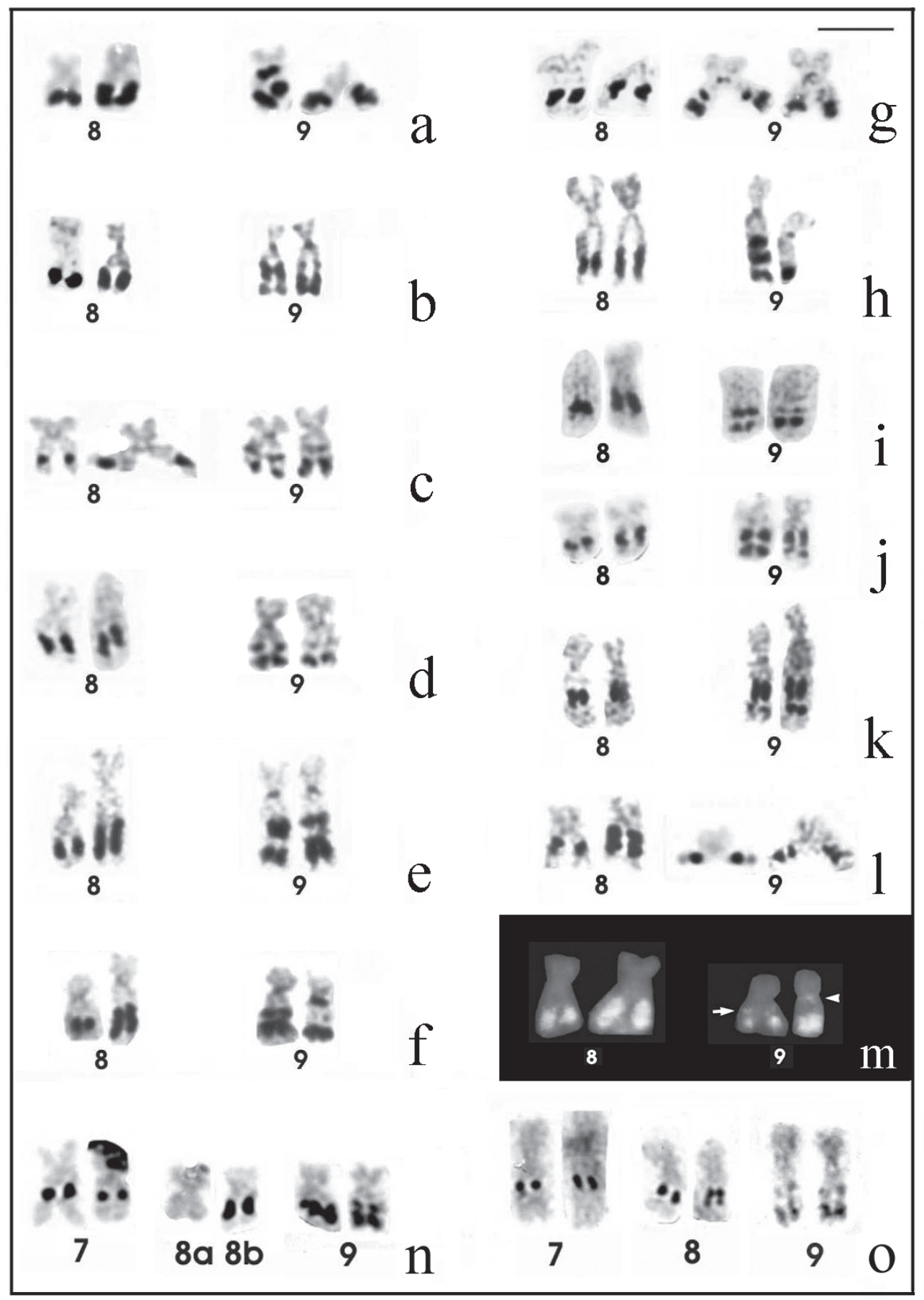

Figure 4: The two NOR- bearing chromosomal pairs (number 8 and 9) from specimens of $P$. cuvieri from (a-h) Urbano Santos, (i-l) Crateús and (n-o) São Pedro da Água Branca, after Ag-NOR staining. The chromosomes shown in $\mathbf{n}$ are also seen in the C-banded karyotype in Fig. 2c. In the São Pedro da Água Branca specimens (n-o) an additional NOR-bearing chromosome was detected (pair 7) by the same technique. In $\mathbf{m}$, the NOR-bearing chromosome pairs 8 and 9 of one $P$. cuvieri specimen from Urbano Santos after FISH with the rDNA probe HM 123. The arrow indicates a small NOR near the centromere of one homologue of pair 9 and the arrowhead indicates an interstitial small NOR in the other homologue of the same chromosomal pair. Note the similarity to the NOR pattern shown by silver staining in $\mathbf{f}$. Bar=5 um. 
interpopulational comparative analysis, the NOR-bearing arm of chromosome 11 was considered as the short one, according to the descriptions reported by Silva et al. (1999, Table 1 of this work) for the karyotypes of $P$. cuvieri populations from the southern (Santa Maria - RS) and the southeastern (Boracéia - SP and Rio Claro $\mathrm{SP})$ regions of Brazil. Additional NORs were found in the long arm of chromosome 1 (Fig. 6c) and near the pericentromeric regions of the chromosome 8 (Fig. 6d) and 7 (Fig. 6e). At difference of the Brazilian populations, no interstitial NOR was detected at pair 8 in the Argentinean specimens.

\subsection{Karyotypes of Brazilian specimens from Tocantins (TO)}

The specimens sampled in Porto Nacional (TO), at the north of Brazil, showed karyotypes that have similar chromosome morphology, to those previously described for all the Brazilian and Argentinean specimens (Fig. 7), but their NOR patterns were very different from those detected in the specimens of all the others populations. In the TO specimens, a larger number of NOR sites were detected by silver staining (Figs. 7a, b) and FISH with the rDNA probe HM 123 (Fig. 7c, d). The NOR sites revealed by both methods were observed in Giemsa stained metaphases as secondary constrictions located in the pericentromeric regions of chromosomes 1, 3, 4, and 10 (Figs. 7a-e) and, in two specimens, also in chromosome 5 (Figs. 7b, d-e). Besides, some heterochromatic regions that were detected by $\mathrm{C}$ banding in the TO specimens (arrowheads in Fig. 7f), also reacted positively with the silver staining technique and hybridized with the rDNA probe HM 123 with the FISH technique (Fig. 7a-d). In

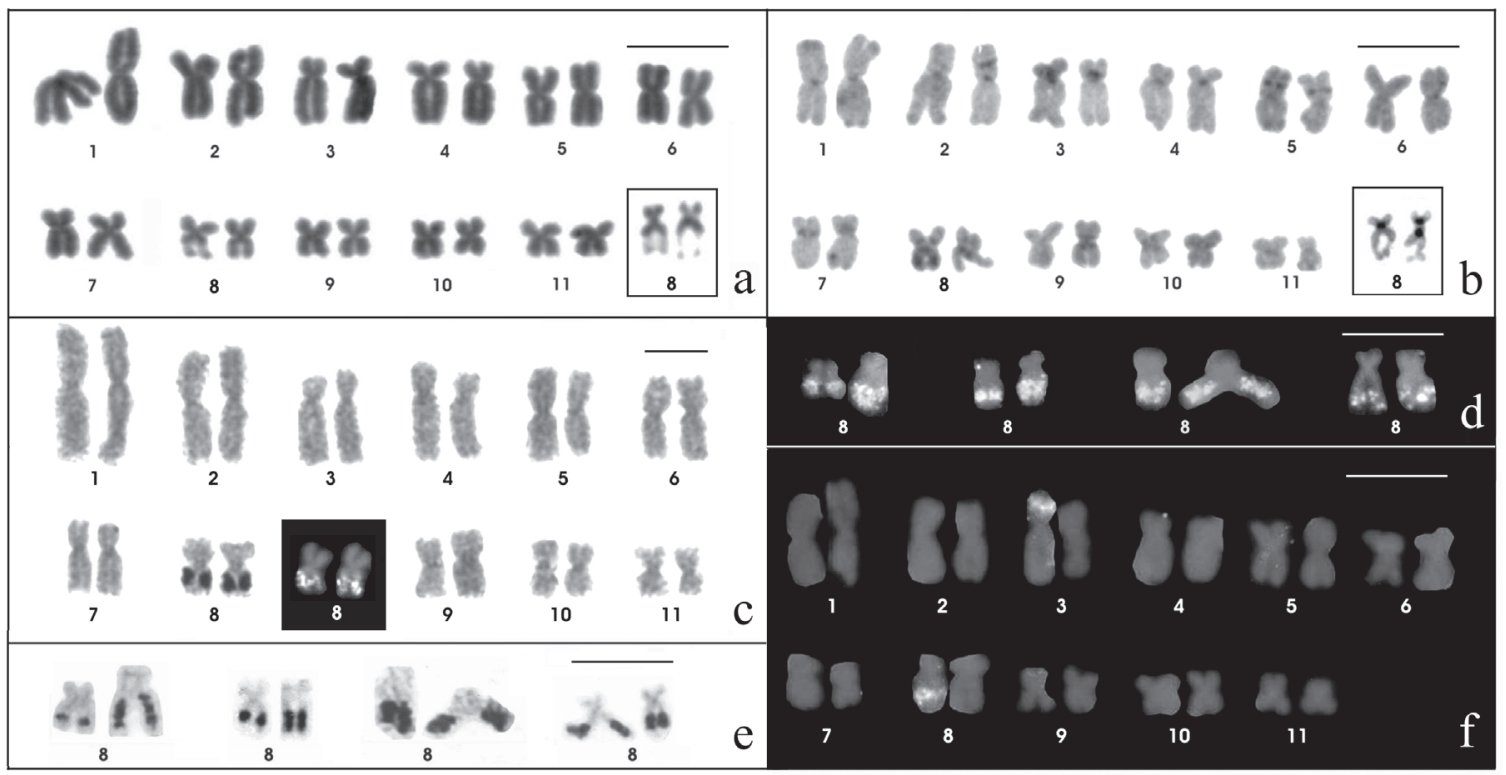

Figure 5: Karyotypes of $P$. cuvieri from Bahia after (a) Giemsa staining, (b) C-banding and (c) AgNOR staining. The insets in $\mathbf{a}$ and $\mathbf{b}$ show the chromosomal pair 8 of $P$. cuvieri from Minas Gerais. In c, the inset shows the NOR-bearing pair after in situ hybridization with an rDNA probe. d-e. NOR- bearing chromosome 8 from different cells of a $P$. cuvieri specimen (ZUEC 13366) from Minas Gerais, which were submitted to (d) FISH with the rDNA probe HM 123 and (e) Ag-NOR staining. Note that variations in NOR sizes were detected by both techniques $(\mathbf{d}, \mathbf{e})$. In $\mathbf{f}$, the karyotype of another P. cuvieri specimen (ZUEC 13368) from MG after FISH with the rDNA probe HM 123. Note the interesting fluorescent signals in the short arm of only one chromosome of pair 3 and one of the homologues of pair 8 . Bar=5 um. 
general, these additional sites were observed either as brown blocks in silver impregnated metaphases, even when the NORs were black, or as small dots in metaphases treated with the rDNA probe. Because of these uncommon characteristics, only the pericentromeric sites in chromosomes $1,3,4,5$ and 10 were considered as constant and typical NORs. C-bands were also revealed at the centromeric region of all the chromosomes, the short arm pericentromeric region of chromosome 7 , the long arm telomeric region of chromosome 1 and as an interstitial band in the short arm of chromosome 5 (Fig. 7f).
4. DISCUSSION

The karyotypes of the P. cuvieri specimens from the different localities examined in the present work were quite similar regarding their chromosome numbers and morphologies $(2 \mathrm{n}=22 ; \mathrm{NF}=44)$. These results are in agreement with previous reports on other species of the genus Physalaemus (Beçak et al., 1970; Denaro et al., 1972; De Lucca et al., 1974; Amaral et al., 2000; Silva et al., 2000). The similarities in chromosome morphology and C-banding pattern were observed mainly in the first seven chromosomal pairs of the karyotype, which seem to be considerably

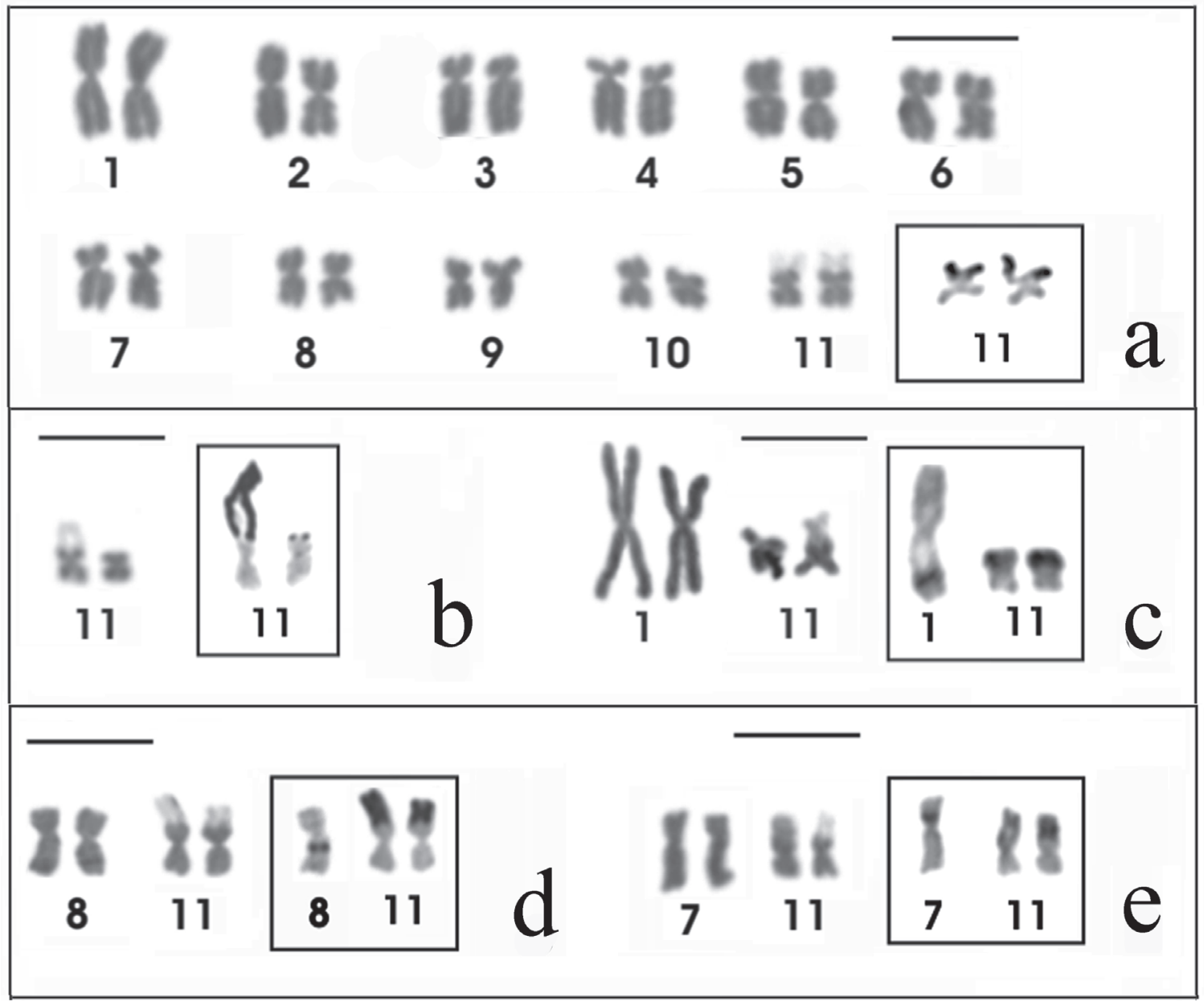

Figure 6: Chromosomes of the five $P$. cuvieri specimens of from the north of Argentina analyzed (a-e) stained by Giemsa or silver impregnated (insets). In b-e, only the NOR-bearing chromosome pairs are shown. Bar=5 um. 
conserved in the Physalaemus genus. The apparent inversion in the ordination of pairs 3 and 4, observed by comparing different karyotypes, most likely was due to inherent variations in the method used for chromosomal size analyses and also the sample used for it, since these pairs were very similar in size).

All $P$. cuvieri specimens showed small amounts of centromeric heterochromatin and a conspicuous interstitial C-band in the short arm of chromosome 5, being so in agreement with a previous report on this same species (Silva et al., 1999). The intensity of an interstitial C-band in the short arm of chromosome 2 varied among the $P$. cuvieri populations, being more evident in the population from Rio Claro (Silva et al., 1999) and in the BA specimens. Such differences may reflect polytypic variations in the size of heterochromatic bands, although the hypothesis that they resulted from technical difficulties in detecting these small C-bands cannot be excluded. An additional difference was observed in a C-band of the short arm of pair 8, which was detected only in the BA specimens. This C-band could be responsible for the metacentric morphology of this chromosome pair in the BA individuals, since in the other analyzed populations the pair 8 was submetacentric.

\subsection{Polytypic and polymorphic variations of NOR}

The detected NOR variation was considerably higher than those of the Cbanding patterns in the $P$. cuvieri karyotypes. In this species, most of the populations so far analyzed showed more than one NOR bearing chromosomal pair. In a previous study, Silva et al. (1999) described a maximum of five NOR-bearing chromosomes localized in four chromosomal pairs of one $P$. cuvieri specimen from the site B in Rio Claro (São Paulo), southeastern Brazil. Although additional NORs were commonly found in the southeastern Brazilian sites studied by

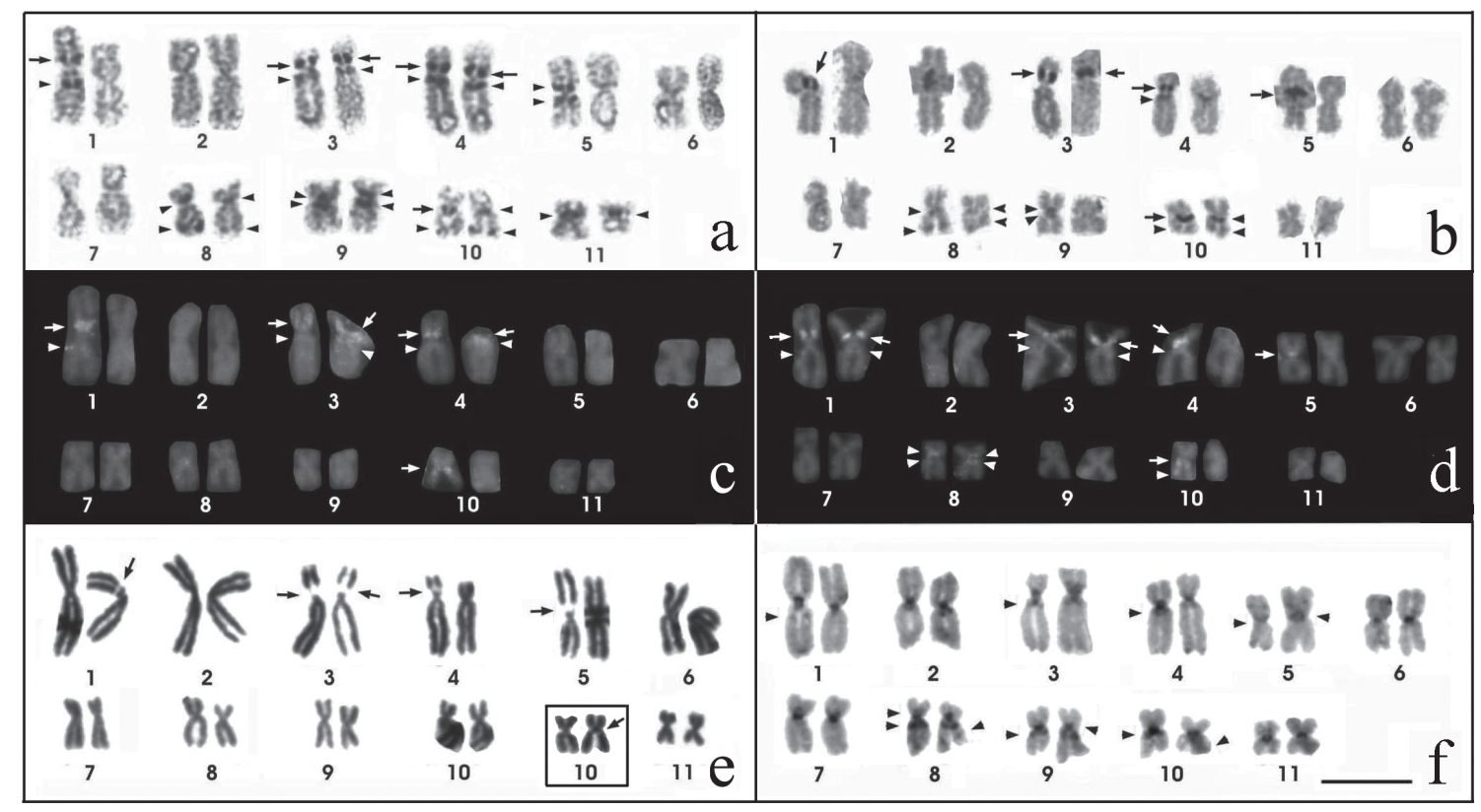

Figure 7: Karyotypes of $P$. cuvieri TO specimens after (a,b) Ag-NOR staining, (c,d) FISH with the rDNA probe HM 123, (e) Giemsa staining and (f) C-banding. The inset in e shows the chromosomal pair 10 of the same individual, with a more evident secondary constriction. The NORs were indicated by arrows in a-e. The arrowheads point other sites detected by $(\mathbf{a}, \mathbf{b}) \mathrm{Ag}-\mathrm{NOR}$ staining and (c,d) FISH, found only in some metaphases of different individuals. Note that these regions were also $\mathrm{C}$-banded (arrowheads in $\mathbf{f}$ ). Bar=5 um. 
Silva et al. (1999), chromosome 8 was the principal NOR bearing chromosome in three of the studied localities from southeastern and south Brazil. On the other hand, in the karyotypes of specimens from Boracéia, São Paulo, southeastern Brazil, and Santa Maria, Rio Grande do Sul (RS), southern Brazil, chromosome 11 was the only NOR-bearing chromosome (Table I and Silva et al., 1999).

In the populations from the northeastern region of Brazil, the long arm of pair 8 always borean interstitial NOR. On the other hand, this NOR of $8 \mathrm{q}$ was not found in the Argentinean populations. In the karyotypes of the specimens from Argentina, the main NOR was located in terminal region of the short arm of chromosome 11 , the same site occupied by the NOR in karyotypes of specimens from Boracéia and Santa Maria (Table I; Silva et al., 1999). This terminal NOR on 11p was also described in five of the six studied specimens from Rio Claro (Silva et al., 1999), but in that case it was not the principal NOR site and the specimens were heterozygous for its presence. In contrast, there was no NOR in the $11 \mathrm{p}$ ter of any specimen from the northern (TO) and northeastern (MA, CE and BA) analyzed Brazilian populations. It is interesting to note that the populations containing a NOR in $8 \mathrm{q}$ int and in $11 \mathrm{p}$ ter, as a fixed condition, represented opposite extremes in the P. cuvieri geographic distribution.

The MA and CE specimens were the only ones with the NOR located on chromosome pair 9 . The high variation in the number and size of NOR sites in these northeastern Brazilian populations generated considerable morphological variation in the chromosome 9. In some cases, a clear distinction between pairs 8 and 9 was possible only by analyzing Cbanded metaphases after silver impregnation since the NORs in pair 9 were also C-banding-positive. A possible explanation for the detection of NORs by C-banding was suggested by King et al. (1990), that based on hylids studies, considered the presence of repetitive sequences, that would be $\mathrm{C}$ positive, in the intergenic spacers of the ribosomal DNA.
These interpopulational divergences allowed a clear distinction between a group of populations from the northeastern Brazil and the populations from the southern Brazil and Argentina. Moreover, there was more similarity among the populations in the transitional area of Amazon-CerradoCaatinga (São Pedro da Água BrancaUrbano Santos-Crateús) than between the two populations from the Cerrado (Urbano Santos-Uberlândia) or from the Caatinga (Crateús-Palmeiras). Because P. cuvieri lives in open areas within these three biomes (for a brief description of these biomes, see http://www.ibge.gov.br/home/ p r e s i d e n c i a / n o t i c i a s/ noticia_visualiza.php?id_noticia=169), the similarities seems to be more related to the geographic distances than with the environmental differences.

The number and chromosomal distribution of the NORs in the specimens of the TO population differed greatly from all the other $P$. cuveri populations, including those that live geographically very near to it. Similarly to the studied population from Rio Claro (Silva et al., 1999) several NOR-bearing chromosomes were present in the TO population, but the typical NOR sites of chromosomes 8 and 11 , commonly found in the other populations of this species, were never detected. NOR sites in the TO specimens were observed always in chromosomal pairs $1,3,4,5$ and 10 . As well, some heterochromatic sites detected in many metaphases from different individuals reacted positively to the silver staining technique and FISH with an rDNA probe. We have hesitated to consider those heterochromatic sites as functional NORs, although they have some homology wih an rDNA probe, because they are generally seen as brown sites in silver impregnated metaphases and as small dots in metaphases hybridized with rDNA. Moreover, they were not always present in the metaphases of the different individuals, or not even in all the metaphases within the same specimen.

Although the Ag-NOR method has been largely used for NOR detection, silver marks that do not correspond to functional 
NORs have been described in several cytogenetic studies (Sumner, 1990; Sánchez et al., 1995; Dobigny et al., 2002) and in some papers such findings have been attributed to the heterochromatic nature of these sites (Nardi et al. 1978, De Lucchini et al., 1997). These data were in accordance with our present interpretation of the results found in $P$. cuvieri TO karyotypes. In the anuran Leptodactylus mystacinus several non-NOR sites were present in silver stained metaphases, but were not detected by FISH with rDNA probe (Silva et al., 2006). The detection of heterochromatic regions by FISH with rDNA probe had been previously reported by Martins et al. (2006). In that study, a probe of $5 \mathrm{~S}$ ribosomal gene detected a satellite DNA in the centromeric regions of the fish Hoplias malabaricus chromosomes The positive signals obtained by FISH with an rDNA probe in the $\mathrm{C}$ positive bands of $P$. cuveri TO karyotypes here described suggest that these heterochromatic sites could be derived from ribosomal genes, similarly to those observed by Martins et al. (2006) for $5 \mathrm{~S}$ rDNA. Further experiments could test this hypothesis and we cannot discard the posibility that those sites are actually small NORs, with few ribosomal cistrons. Despite the intriguing nature of these sites, they were found exclusively in the TO specimen karyotypes and could be considered as a distinguishing characteristic of this population.

\subsection{Intraindividual variation in the NOR site}

Inter- and intrapopulational variation in NOR size is common in anurans (Schmid, 1982; Lourenço et al., 1998; 2003; Silva et al., 1999; Wiley, 2003; Siqueira-Jr et al., 2004). However, intraindividual variations in NOR are rare in these amphibians. Silva et al. (1999) reported intraindividual variation in the Ag-NOR pattern of two $P$. cuvieri specimens from Rio Claro (SP), attributing this variation to differential regulation in the expression of ribosomal genes. In the present work, the MG specimens showed intraindividual variation in the size of the chromosome 8 NOR, which was detected by both Ag-NOR staining and FISH with rDNA probe. Because this size variation was detected by both techniques, we suggest that it corresponds to real size diversity in the NOR site instead of differential regulation of its expression. Unequal sister chromatid exchange is commonly suggested as a mechanism responsible for the occurrence of amplifications/deletions in NORs (Motovali-Bashi et al., 2004) and can account for the size variation described herein. FISH analysis also revealed additional intraindividual variation of chromosome 3 in some metaphases of one MG specimen. Although this site was not detected by Ag-NOR staining and was detected only sporadically by FISH, the possibility that it may correspond to an active NOR cannot be excluded.

\subsection{Concluding remarks}

The NOR pattern diversity of the $P$. cuvieri frog populations from several regions of Brazil and Argentina allowed the identification of variations along the geographic distribution of $P$. cuvieri and some population groups could be recognized. One of them includes the populations from Urbano Santos (MA), São Pedro da Água Branca (MA) and Crateús $(\mathrm{CE})$, in the northeast region of Brazil. On the other hand, the comparative analysis of the NOR, C band patterns and FISH signal after hybridization with an RNA probe, showed that the karyotype of the TO specimens, in the northern region of Brazil, greatly differed from all of the other $P$. cuvieri populations analyzed so far. The data presented herein revealed substantial geographic polytypic variation in the $P$. cuvieri species and indicated that a taxonomic review of this species is necessary. This review can be improved through further morphological and acoustic assessments.

\section{ACKNOWLEDGEMENTS}

The authors are grateful to Ana Cristina Prado Veiga-Menoncello, Ana Paula Z. 
Silva de Pietri and Cynthia P. A. Prado for critically reviewing the manuscript, to Klélia A. Carvalho for technical assistance, to Sérgio Siqueira Júnior for helping with frog specimen sampling in Porto Nacional (TO) and Uberlândia (MG) and to Maria Lúcia Del Grande for helping with frog specimen sampling in Palmeiras (BA). This work was supported by FAPESP (Fundação de Amparo à Pesquisa do Estado de São Paulo), CNPq (Conselho Nacional de Desenvolvimento Científico e Tecnológico) and ANPCyT (Agencia Nacional de Promoción Científica y Tecnológica, Argentina: PICT 16-35045 and PICT-O 37035). The Brazilian specimens were sampled under a permit issued by the Instituto Brasileiro do Meio Ambiente e dos Recursos Naturais Renováveis (IBAMA, Proc. No. 02010.002895/03-84), and the Argentinean specimens were sampled under a permit issued by the Ministerio de Ecología, Recursos Naturales Renovables y Turismo de la Provincia de Misiones.

\section{REFERENCES}

AMARAL MJLV, CARDOSO AJ, RECCO-PIMENTEL SM (2000) Cytogenetic analysis of three Physalaemus species (Amphibia, Anura). Caryologia 53:283-288

BARRETO LN, ANDRADE GV (1995) Aspects of the reproductive biology of Physalaemus cuvieri (Anura: Leptodactylidae) in northeastern Brazil. AmphibiaReptilia 16:67-76.

BEÇAK ML, DENARO L, BEÇAK W (1970) Polyploidy and mechanisms of karyotypic diversification in Amphibia. Cytogenetics 9:225-238.

CEI, JM (1980) Amphibians of Argentina. Monitore Zoologico Italiano (n.s.). Monografia 2:609 pp.

DENARO L (1972) Karyotypes of Leptodactylidae anurans. J Herpetol 6: 71-74.

DE LUCCA, EJ (1974) Chromosomal studies in twelve species of Leptodactylidae and one Brachycephalidae. Caryologia 27:183-191

DE LUCCHINI S, ANDRONICO F, NARDI I (1997) Molecular structure of the rDNA intergenic spacer (IGS) in Triturus: implications for the hypervariability of rDNA loci. Chromosoma 106: 315-326.

DOBIGNY G, OZOUF-COSTAZ C, BONILLO C, VOLOBOUEV V (2002) "Ag-NORs" are not always trues NORs: new evidence in mammals. Cytogenet Genome Res 98:75-77.

FROST DR (2007) Amphibians species of the world: an online reference. V5.0 (February 1, 2007) Electronic database available at: http://research.amhn.org/ herpetology/amphibia/index.html.

GRANT T, FROST DR, CALDWELL JP, GAGLIARDO R, HADDAD CFB, KOK PJR, MEANS DB, NOONAN BP, SCHARGEL WE, WHEELER WC (2006) Phylogenetic systematics of dart poison frogs and their relatives (Amphibia: Athesphatanura: Dendrobatidae). Bulletin AMNH 299:1-262.

HOWELL WM, BLACK DA (1980) Controlled silver staining of nucleolus organizer regions with a protective colloidal developer: a 1-step method. Experientia 36:1014-1015.

KING M (1980) C-banding studies on Australian hylid frogs: secondary constriction structure and the concept of euchromatin transformation. Chromosoma 80:191217.

KING M, CONTRERAS N, HONEYCUTT RL (1990) Variation within and between nucleolar regions in Australian hylid frogs (Anura) shown by $18 \mathrm{~S}$ and $28 \mathrm{~S}$ in situ hydridization. Genetics 80:17-29.

LOURENÇO LB, RECCO-PIMENTEL SM, CARDOSO AJ (1998) Polymorphisms of the nucleolus organizer regions (NORs) in Physalaemus petersi (Amphibia, Anura, Leptodactylidae) detected by silver staining and fluorescence in situ hybridization. Chromosome Res 6:621-628.

LOURENÇO LB, GARCIA PCA, RECCO-PIMENTEL SM (2003) Intrageneric karyotypic divergence in Scythrophrys and new insights into the relationship with Paratelmatobius (Anura, Leptodactylidae). Ital J Zool 70:183-190.

MANZANO AS, BALDO D, BARG M (2004) Anfibios del Litoral Argentino. Temas de la Biodiversidad del Litoral fluvial argentino INSUGEO, Miscelánea, 12:512 .

MARTINS C, FERREIRA IA, OLIVEIRA C, FORESTI F, GALETTI PM (2006) A tandemly repetitive centromeric DNA sequence of the fish Hoplias malabaricus (Characiformes: Erithrinidae) is derived from 5S rDNA. Genetica 127:133-141.

MEUNIER-ROTIVAL M, CORTADAS J, MACAYA G, BERNARDI $G$ (1979) Isolation and organization of calf ribosomal DNA. Nucleic Acids Res 6:2109-2123.

MOTOVALI-BASHI M, HOJATIA Z, WALMSLEYB RM (2004) Unequal sister chromatid exchange in the rDNA array of Saccharomyces cerevisiae. Mutation Res 564:129-137

NARDI I, DE LUCCHINI S, BARSACCHI-PILONE G, ANDRONICO F (1978) Chromosome location of the ribosomal RNA genes in Triturus vulgaris meridionalis (Amphibia, Urodela). Chromosoma 70: 91-99.

NASCIMENTO LB, CARAMASCHI U, CRUZ CAG (2005) Taxonomic review of the species groups of the genus Physalaemus Fitzinger, 1826 with revalidation of the genera Engystomops Jiménez-de-La-Espada, 1872 and Eupemphix Steindachner, 1863 (Amphibia, Anura, Leptodactylidae). Arq Mus Nac Rio de Janeiro 63:297-320.

SÁNCHEZ A, JIMÉNEZ R, BURGOS M, SITTOU S, ZURITA F, DE LA GUARDIA RD (1995) Cytogenetic peculiarities in the Algerian hedgehog: silver stains not only NORs but also heterochromatic blocks. Heredity 75:10-16

SCHMID M (1978) Chromosome banding in Amphibia. I. Constitutive heterochromatin and nucleolus organizer regions in Bufo and Hyla. Chromosoma 66:361-388.

SCHMID, M (1982) Chromosome banding in Amphibia. VII. Analysis the structure and variability of NORs in Anura. Chromosoma, 87:327-344.

SCHMID M, OLERT J, KLETT C (1979) Chromosome banding in Amphibia. III. Sex chromosomes in Triturus. Chromosoma 71:29-55.

SILVA APZ, HADDAD CFB, KASAHARA S (1999) Nucleolus organizer regions in Physalaemus cuvieri (Anura, Leptodactylidae), with evidence of a unique case of Ag-NOR variability. Hereditas 131:135-141. 
SILVA APZ, BALDISSERA-JR FA, HADDAD CFB Kasahara S (2000) Karyotypes and nucleolus organizer regions of the genus Physalaemus (Anura, Leptodactylidae). IheringiaSér Zool 88:159 164.

SILVA APZ, HADDAD CFB, GALASSI GG, KASAHARA S (2006) Multiple nucleolus organizer regions in Leptodactylus mystacinus (Amphibia, Anura) and comments on its systematic position in the L. fuscus group based on cytogenetic and molecular analyses. Genetica 127:35-44.

SUMNER AT (1990) Chromosome Banding. Unwin Human Ltd, London.

SIQUEIRA-JR S, ANANIAS F, RECCO-PIMENTEL SM
(2004) Cytogenetics of three Brazilian species of Eleutherodactylus (Anura, Leptodactylidae) with 22 chromosomes and reanalysis of multiple translocation in E. binotatus. Genet Mol Biol 27:363-372.

VIEGAS-PÉQUIGNOT E (1992) In situ hybridization to chromosomes with biotinylated probes. In: WILLERNSON D (ed) In Situ Hybridization: A Practical Approach. Oxford University: Press IRL Press, Oxford, pp:137-158.

WILEY JE (2003) Replication banding and FISH analysis reveal the origin of the Hyla femoralis karyotype and $\mathrm{XY} / \mathrm{XX}$ sex chromosomes. Cytogenet Genome Res 101:80-83. 